\title{
Seasonal Prevalence of Gastro-Intestinal Helminth Parasites of Goats (Capra Sp.) of Shivraj Municipality-13 Kapilvastu, Nepal
}

\author{
Rabindra Prasad Tripathi and Janak Raj Subedi \\ Central Department of Zoology, Tribhuvan University, Kirtipur, Kathmandu, Nepal \\ For Correspondence: janzoology@gmail.com
}

\begin{abstract}
Goat (Capra sp.), an important source of meat is greatly affected by the helminth parasites. The current study aimed to determine the seasonal prevalence of intestinal helminthes parasites using sedimentation and flotation techniques. The overall prevalence of helminthes parasite found to be $58(54.71 \%)$ and 86 $(81.13 \%)$ for the winter and summer respectively. Fecal samples collected during winter season revealed the presence of trematodes (12.26\%), cestodes (6.66\%), and nematodes (35.84\%) and other $6.31 \%$. Similarly the fecal samples collected during summer season revealed presence of helminth eggs including trematodes $(17.92 \%)$, cestodes $(10.37 \%)$ and nematodes $(52.83 \%)$ nematodes. The prevalence percentages of identified genera of trematodes were Dicrocoelium sp. (3.47\%), Fasciola sp. (15.97\%) and Paramphistomum sp. (2.77\%). The difference in the prevalence of different genera of trematodes during winter and summer were not found statistically insignificant $(\chi 2=1.325, \mathrm{p} 0.250)$. Among cestodes the only one genus identified with were Moniezia sp. (2.77\%) and Taenia sp. (9.72\%). The difference in the prevalence of different genera of cestodes during winter and summer were not found statistically insignificant $(\chi 2=2.186, \mathrm{p} 0.139)$.

Similarly the identified nematode genera included Toxocara sp. (16.66\%), Strongyl sp. (1.38\%), Bunostomum (2.77\%), Capillaria (4.86\%), Chabertia (4.16\%), Cooperia (2.08\%), Heamonchus (3.47\%), Oesophagostomum (8.33\%), Nematodirus (0.69\%), Ostertagia (1.38\%), Strongyloides (6.25\%), Trichuris (5.55\%), Trichostrongylus $(4.86 \%)$ and others $(4.86 \%)$. Mixed infection was observed in out of a total of $134(63.20 \%)$ mixed infection 54 (50.94\%) and 80 (75.47\%) samples showed helminthes eggs during winter and summer season were respectively detected. The difference in the prevalence of helminth parasites during winter and summer seasons were found statistically significant $(\chi 2=6.193, \mathrm{P}<0.013, \mathrm{~d}$. $\mathrm{f}$. $=1)$
\end{abstract}

Key words: Helminth, Trematodes, Cestodes, Nematodes, Parasite, Prevalence, Sedimentation, Flotation.

\section{Introduction}

Goat (Capra sp.) belongs to family bovine and subfamily caprinae, is one of the important oldest domesticated small ruminant, raised mainly for meat, dairy, and manure. The animal is widely distributed all over the world. The national production is unable to fulfill the need of Nepal; hence significant numbers of goats are imported from neighboring countries. About $74 \%$ of goats are brought from India and 26\% from different parts of Nepal in the Kathmandu market ( $3^{\text {rd }}$ NASc Conv., 1998/1999). Livestock

Nepalese Journal of Zoology| Online Volume 3 Issue 1 | November 2015 | Page 71 
farming is an integral part of the farming system and goats contribute substantially in the livestock sector of Nepal.

Goats are very much prone to the infection of gastrointestinal helminthes parasites. The parasites cause more than 20 percent loss in the production and productivity of animal. It is very important to know the status helminthes in various geoclimatic conditions in order to design an appropriate prevention and control strategies. Therefore present study aimed at the determination of the status of gastrointestinal helminthes in buffaloes.

\section{Materials and Methods}

The study area "Shivraj Municpality-13" Balanagar is the one of the village of Kapilvastu district of Nepal, where people kept many domestics animals including goats mainly for meat and income generation purpose. It's about $330 \mathrm{~km}$ west for the capital city Kathmandu. The goats are supplied from this place to slaughter house of Khasibazar, Chandrauta, Kapilvastu.

The present study was carried out in May/June (summer) 2012 and December/January (winter) 20122013.The site of collection of samples was Shivraj Municpality-13, Kapilvastu, Lumbini.

The study was aimed to determine the seasonal prevalence of helminth parasites in goats. A total of 212 fecal samples including 106 each collected during winter and summer season were collected from the study area and preserved in $2.5 \%$ potassium dichromate. The samples were tested at the laboratory of Central Veterinary Hospital, Kathmandu using both sedimentation and flotation method. The eggs of different genera of helminthes were identified according to their size, shapes and other morphological features as observed in microscope.

\section{Results}

Out of total 212 fecal samples tested, $144(67.92 \%)$ samples showed the presence of helminth eggs with flotation and sedimentation technique. The seasonal difference of negative samples were found statistically insignificant $(\chi 2=3.118, \mathrm{p} 0.077)$.

Among the positive samples, the trematode, cestode and nematode eggs were detected in $32(22.22 \%), 18$ $(12.50 \%)$ and $94(65.27 \%)$ samples. Out of a total of 106 fecal samples, the helminth eggs were detected in $58(54.71 \%)$ and $86(81.13 \%)$ samples collected during winter and summer season respectively.

A total of 17 helminthes genera identified included 3 trematodes, 2 cestodes and 12 nematodes. The prevalence of each of those helminth parasites has been given in Table 1. The prevalence of helminth was found more during summer $81.13 \%$ than in winter $54.71 \%$. The seasonal prevalence of different genera of helminth parasites were found statistically insignificant $(\chi 2=3.118, \mathrm{p}=0.077)$.

Out of 106 samples tested, 32 (22.22\%) samples including 19 (17.92\%) and $13(12.26 \%)$ samples tested during summer and winter respectively showed trematode eggs. The 13 trematode positive samples of winter season, included Fasciola (11 or $10.37 \%)$ and Dicrocoelium (2 or 1.88\%) sp. Similarly 19 trematode positive samples of summer season include Fasciola sp.(12 or 11.32\%), Paramphistomum sp. (4 or 3.77\%) and Dicrocoelium sp. (3 or 2.83\%). Prevalence of Fasciola (15.97\%) was found to be the highest followed by Dicrocoelium (3.47\%) and Paramphistomum (2.72\%). The seasonal prevalence of various trematodes were found statistically insignificant $(\chi 2=1.325, \mathrm{p} 0.25)$.

Out of 106 samples tested during summer and winter, altogether 18 (12.50\%), including 8 (7.54\%) summer and $6(5.66 \%)$ winter samples, were found positive for cestodes. The genera of Taenia and

Nepalese Journal of Zoology | Online Volume 3 Issue 1 | November 2015 | Page 72 
Moniezia were identified in $4(3.77 \%)$ samples. The seasonal prevalence of various cestodes were found statistically insignificant $(\chi 2=2.186, \mathrm{p}=0.139)$.

Out of the total samples 94 (65.27\%) samples showed nematode eggs including Toxocara, Bunostomum, Oesophagostomum, Chabertia, Capillaria, Heamonchus, Cooperia, Strongyloides, Trichuris, Trichostrongylus and Ostertagia. (Table 1). The highest and lowest prevalence was shown by Toxocara $(16.66 \%)$ and Ostertagia $(1.38 \%)$ sp. respectively. 6.31\% samples showed nematodes that could not be identified. The seasonal prevalence of various nematodes were found statistically insignificant $(\chi 2=$ 6.193, $\mathrm{P}<0.013$, d. f. $=1$ ).

Table1. Prevalence of various helminth genera

\begin{tabular}{|l|l|l|l|}
\hline S.N & Class & Genera of helminth & $\begin{array}{l}\text { Prevalence } \\
\text { Percentage }\end{array}$ \\
\hline & Trematoda & Fasciola & $15.97 \%$ \\
\hline & (Total positive: 32) & Dicrocoelium & $3.47 \%$ \\
\hline & & Paramphistomum & $2.77 \%$ \\
\hline & Cestoda & Taenia sp & $9.72 \%$ \\
\hline & (Total positive: 18) & Moniezia & $2.77 \%$ \\
\hline & & & \\
\hline & Nematoda & Toxocara & $16.66 \%$ \\
\hline & (Total positive: 94$)$ & Bunostomum & $2.77 \%$ \\
\hline & & Chabertia & $4.16 \%$ \\
\hline & & Capillaria & $4.86 \%$ \\
\hline & & Oesophagostomum & $8.33 \%$ \\
\hline & & Heamonchus & $3.47 \%$ \\
\hline & Cooperia & $2.08 \%$ \\
\hline & & Strongyloides & $6.25 \%$ \\
\hline & & Trichuris & $5.55 \%$ \\
\hline & & Trichostrongylus & $4.86 \%$ \\
\hline & & Ostertagia & $1.38 \%$ \\
\hline & & Others & $6.31 \%$ \\
\hline & &
\end{tabular}

A higher rate of mixed infection was found during summer season (134 or 63.20\%) as compared to that of winter (54 or $50.94 \%)$ samples.

Light infection (+) was found in 5 Fasciola positive samples whereas mild (++) infection was shown by 5 Toxocara positive samples. Moderate infection (+++) was shown by 4 Toxocara positive samples and heavy infection 1 (++++) was shown by 1 Taenia, 1 Fasciola and 1 Toxocara positive samples.

\section{Discussion and Conclusion}

Out of total 212 samples tested, $86(81.13 \%)$ and $58(54.71 \%)$ samples showed the presence of helminthes eggs in summer and winter season respectively indicating that the parasites were infecting the goats throughout the years.

Present study showed a prevalence of trematode (22.22\%), cestode (11.08\%) and nematode $(65.27 \%)$. Opara et al. (2005) reported a prevalence of trematode (78.4\%), cestodes (13\%) and nematode (8.7\%)

Nepalese Journal of Zoology| Online Volume 3 Issue 1 | November 2015 | Page 73 
respectively in Nigeria. Presence of suitable temperature and moisture and availability of intermediate host could be the reason behind higher prevalence of certain helminth parasites during summer season.

Present study showed a higher prevalence of nematodes $(65.27 \%)$, cestodes $(11.08 \%)$, and trematodes (22.22\%) which somehow corroborated to the findings of Ijaz et al. (2008) who showed highest infection rate of nematodes (42.67\%) followed by trematodes (16.67\%) and cestodes (4\%) in Lahore, Pakistan.

A research by Wanjala et al. (2002) in the month of May/June and August /September showed 52\% infection of helminths in small ruminants in pastoral community in Kenya.

In the present study, 3 genera of trematodes, 2 genera of cestodes and 14 genera of nematodes were identified. Among trematodes Fasciola, was common during both winter and summer season but Dicrocoelium was found only during winter season and Paramphistomum in summer only. Present study exhibited $10.37 \%$ and $11.32 \%$ prevalence of fascioliasis during winter and summer season respectively. The increase in the prevalence during summer may be due to increase in humidity and availability of favorable temperature. High prevalence of Fasciola was reported from Surkhet among goats (Ghimire 1987) followed by 58\% from Chitwan district (Dhakal and Kharel 1988), 31.25\% infection from Dhanusa district (Jaiswal 2006). Similarly, the prevalence of Dicrocoelium was reported to be $1.88 \%$. that corroborated with the earlier finding of Jithendran (1997). Present study recorded a $2.77 \%$ prevalence of Paramphistomum in summer samples.

Among cestodes, Moniezia was found only in summer and Taenia found in both seasons. Moniezia has been reported from Kathmandu and Surkhet district among buffaloes, sheep, goat and cattle (Ghimire 1987). In the present study, Moneizia has been reported only in summer only.

The findings of present study regarding the prevalence of nematodes included Toxocara, Bunostomum, Chabertia, Capillaria, Oesophagostomum, Heamonchus, Cooperia, Strongyloides, Trichuris, Trichostrongylus and Ostertagia. However, Bunostomum and Ostertagia were not observed during winter season. Mankir (2007) reported highest prevalence rate of Haemonchus followed by Trichostrongylus in goats and sheep in Ethiopia. The difference in the result could be due to the variation in weather conditions and humidity in atmosphere.

Yadav et al. (2005) reported the highest prevalence of Heamonchus, Trichostrongylus, Bunostomum, Oesophagostomum and Strongyloides.

In the current study, the rate of mixed infection was also observed. Among 144 (67.92\%) positive samples, $134(63.20 \%)$ samples were found to have mixed infection. During winter and summer 54 $(50.94 \%)$ and $80(75.47 \%)$ mixed infection had been shown out of 106 samples. In the current study, the rate of mixed infection was also observed. Among 144 (67.92\%) positive samples, 134 (63.20\%) samples were found to have mixed infection.

\section{Acknowledgements}

We are greatly thankful to all persons who helped to complete this study. Special thanks to Anju Bhusal.

\section{References}

Dhakal, I.P. and Kharel, M. 1988. Common disease of livestock in Chitwan district of Nepal. Journal of institute of Agriculture and Animal sciences, 9:69-74.

Ghimire, N.P. 1987. Incidence of common diseases of cattle and buffaloes in Surkhet district. Bulletin of Veterinary Science and Animal Husbandary, Nepal, 15: 95-101.

Nepalese Journal of Zoology | Online Volume 3 Issue 1 | November 2015 | Page 74 
Ijaz, m., Khan, M.S., Avanis, M., Asharf, K., Ali, M.M and Saima. 2008. Infection Rate and chemotherapy of various Helminths in goats in and around Lahore. Pakistan Vet. J., 28(4):167-170.

Jaisawal, L. K. 2006. Study of fascioliosis in ruminants at Dhunasa district. The Blue Cross, 8:122.

Jithendran, K.P. 1997. Helminth parasites. A constraint in animal health managementin Himanchal Pardesh.

Mankir, M.S. 2007. Epidemiology and anthelmintic resistance and its management. Doctoral thesis, Swedish University of Agricultural Sciences, Uppsala, Sweden.

Mukhiya, G. 2007. A study on intestinal helminth parasites of buffaloes brought to satungal (Kathmandu) for slaughter purpose. M.sc. Thesis submitted to CDZ, T.U., 1:20

Opera, M.N., Nwaobasi, J.K. and Okoli, I.C. 2005. Occurrence of parasitic helminth among small ruminants reared under traditional husbandary system in owerri, South east Nigeria, bulletin of animal health and production in Africa, 53: 226-233

Wanjala, K; Chemuluti, J; Wesonga, F.D. Munga, L; Negere, P; Murrrila, GA and Wesongah, JO 2002. Prevalence of parasitic infections in small ruminants in a pastoral community in Narok districts, Kenya. http://www.jarvm.com

Yadav, C.L.; Banarjee, P.S; Garg, Y. and Vastsya, S. 2005. All India network program on gastrointestinal parasitism establishment of epidemiology of important parasitic disease. http://www.helminthparasitespectruminnorth-eastindia.com. 